\title{
Macrosomia at the Center Hospital of Montelimar (France): 141 Cases Report
}

\section{Ignace N'guessan Yao1*, Paul Eric Kouamé Bohoussou1, Michelle Messou Menin², Gaia Gianola3 , Eva Bazan ${ }^{3}$, Pierre Dirix ${ }^{4}$}

${ }^{1}$ Department of Obstetrics and Gynecology, Treichville University Hospital, Abidjan, Côte d'Ivoire

${ }^{2}$ Department of Obstetrics and Gynecology, Bouaké University Hospital, Bouaké, Côte d'Ivoire

${ }^{3}$ Department of Obstetrics and Gynecology, Montélimar Hospital, Montélimar, France

${ }^{4}$ Department of Obstetrics and Gynecology, Valréas Hospital, Valréas, France

Email: *yaoignacen@yahoo.fr

How to cite this paper: Yao I.N., Bohoussou P.E.K., Menin M.M., Gianola, G., Bazan, E. and Dirix, P. (2017) Macrosomia at the Center Hospital of Montelimar (France): 141 Cases Report. Open Journal of Obstetrics and Gynecology, 7, 966-972.

https://doi.org/10.4236/ojog.2017.79098

Received: July 1, 2017

Accepted: September 19, 2017

Published: September 22, 2017

Copyright () 2017 by authors and Scientific Research Publishing Inc. This work is licensed under the Creative Commons Attribution-NonCommercial International License (CC BY-NC 4.0). http://creativecommons.org/licenses/by-nc/4.0/

\begin{abstract}
Introduction: Macrosomia is usually defined by the delivery of a child over $4000 \mathrm{~g}$ at term. Because of the margins of error, the obstetrician must take into account, in addition to ultrasound, the constitutional and acquired factors of the mother in order to be able to prevent the complications expected during the delivery of a large fetus. Material and method: We carried out a cross-sectional, descriptive, 12-month study in a level 2 hospital in southern France (Montélimar). The aim of the study was to assess the prevalence of macrosomia, to identify the epidemiological characteristics of the patients, to specify the management of obstetrics and complications in this hospital. Results: We recorded 141 births with a weight greater than or equal to $4000 \mathrm{~g}$. That is a rate of $7.95 \%$. The average age of our patients is 30 years. Half of them had a BMI of less than 25 and were not diabetic. $75 \%$ of the patients gave birth by a low-dose route. The sex ratio of the children is male to female 2:1. The main maternal complications were the perineovaginal tears (39 cases) and the hemorrhages of the deliverance ( 6 cases). Conclusion: The delivery of macrosomia is not uncommon at the Hospital Center of Montélimar. It predominates among Caucasians. Usual risk factors have rarely been found. Overall management was without major complications for both the mother and the child.
\end{abstract}

\section{Keywords}

Macrosomia, Risk Factors, Complications, C.H. Montélimar 


\section{Introduction}

The mean weights of children at birth range from $2400 \mathrm{~g}$ in Lumis of New Guinea to $3830 \mathrm{~g}$ in Cheyennes [1]. If some authors retain the limit of $4500 \mathrm{~g}$ or more, it's classically admitted that a child is macrosomia when his weight at birth is more than $4000 \mathrm{~g}$. For some practical reasons, the classical definition of macrosomia is that we have chosen as the most interesting: indeed, most of the feared mechanical complications in high-weight children are eventually met. Knowing the margin of error of ultrasound in the antenatal diagnosis of the macrosomia, the obstetrician is confronted in late pregnancy with hesitations in the face of the best obstetric attitude to adopt. The main fear is the dystocia of the shoulders, which constitutes the obsession of every birth attendant even experienced. It is in the interest of a good screening of this macrosomia in the end of the pregnancy which, in addition to the ultrasound must consider several factors: constitutional and acquired of the mother. The risk factors of macrosomia have been known and described for a long time [2], the socio-demographic and environmental contexts of the populations have often evolved giving the impression of new risk factors that are still of interest in studies on macrosomia. This is why we made this study to assess epidemiological characteristics; Obstetric management and morbidity related to this macrosomia at the maternity hospital of Montelimar in the South of France. The Montelimar hospital center is a level 2 reference center that has recourse to level 3 reference centers. It makes any service combined, 150000 admissions per year.

\section{Patients and Methods}

Our study is a descriptive and transversal study concerning born of macrosomia been at the Hospital Center of Montélimar (France) from January to December 2014. We considered children born at term (37SA and more) from $4000 \mathrm{Gram}$ in the maternity. The purpose of this study was to evaluate the prevalence of macrosomia at the Montélimar maternity center, to identify the anthropometric and epidemiological characteristics of the patients, and to specify the obstetrical care. The anthropo-morphological and epidemiological characteristics of the mother (age, weight, BMI, geographical origin, gesture and parity), maternal history (diabetes, gestational diabetes, Large fetuses), as well as maternal and fetal delivery patterns and complications were evaluated.

The data were collected on a standardized survey form based on patient records on the various registries of the service. Data processing was done using SPSS software.

\section{Results}

\subsection{Frequency}

During the study period, we recorded 141 newborns over 4000 g out of 1773 deliveries in the service. This makes a macrosome rate of $7.95 \%$. 
If we take into account that newborns over $4500 \mathrm{~g}$, the frequency is $1.29 \%$ of all deliveries.

Moreover, $83.68 \%$ (118 cases) of the macrosomes had a weight between 4000 and $4499 \mathrm{~g}$.

\subsection{Anthropometric and Epidemiological Characteristics}

The anthropometric characteristics of the patients concerned their geographical origin, age, body mass index and weight gain. Epidemiological characteristics related to parity and gesture (Table 1).

\subsection{Antecedents}

History of diabetes was found in 4 patients (2.83\%). 15 patients (10.63\%) had suffered from gestational diabetes and $27 \%$ (38 cases) had an history of macrosomia delivery

\subsection{Clinical Characteristics of Pregnancy and Modalities of Delivery}

$82.22 \%$ of patients (116 cases) who gave birth to macrosomes had no gestational diabetes. Half of them (49.65\%) took between 13 and $20 \mathrm{~kg}$ of weight during pregnancy.

Table 1. Epidemiological and anthropometric characteristics.

\begin{tabular}{|c|c|c|}
\hline & Number & Percentage (\%) \\
\hline \multicolumn{3}{|l|}{ Origins } \\
\hline Europe & 96 & 68.1 \\
\hline Maghreb & 41 & 29.1 \\
\hline Black Africa & 04 & 2.8 \\
\hline \multicolumn{3}{|l|}{ Age (an) } \\
\hline $18-24$ & 21 & 14.90 \\
\hline $25-35$ & 87 & 61.70 average. 30 \\
\hline \multicolumn{3}{|l|}{ extremes: 18 - 41} \\
\hline$>35$ & 33 & 23.40 \\
\hline \multicolumn{3}{|l|}{ BMI } \\
\hline$<25$ & 77 & 54.61 \\
\hline $26-30$ & 34 & 24.11 average. 26.42 \\
\hline \multicolumn{3}{|l|}{ extremes: $17-47$} \\
\hline$>31$ & 30 & 21.28 \\
\hline \multicolumn{3}{|l|}{ Gestity } \\
\hline $1-2$ & 63 & 44.7 \\
\hline $3-4$ & 64 & 45.4 average. 2.88 extremes : \\
\hline \multicolumn{3}{|l|}{$1-9$} \\
\hline$>5$ & 14 & 9.9 \\
\hline \multicolumn{3}{|l|}{ Parity } \\
\hline $1-2$ & 98 & 69.5 \\
\hline $3-4$ & 38 & 26.9 average. 2.25 \\
\hline \multicolumn{3}{|l|}{ extrêmes: $1-8$} \\
\hline$>5$ & 5 & 3.6 \\
\hline
\end{tabular}


All of our patients gave birth after 37 weeks with $68.10 \%$ (96 patients) between 40 and 41SA +6 days.

$3 / 4$ of the deliveries were done by normal childbirth with $78.30 \%$ (106 patients) spontaneously. The other deliveries were after a triggering from the 40th week. $1 / 3$ of the triggering was unsuccessful and the Caesarean section was the delivery route. On the 37 Caesarean patients, $62 \%$ were in emergency. The other Caesarean sections were programmed because of fetal pelvic disproportion.

Normal deliveries occurred in epidurals in $75.47 \%$ of cases (80 patients). And $79 \%$ (84) of her patients did not need episiotomy. On the other hand, $14.83 \%$ (14 cases) of deliveries by the normal delivery were made by instrumental extraction (suction cup or forceps).

\subsection{Characteristics of Newborns}

Only 22 cases (15.60\%) of the macrosomes had a weight greater than or equal to 4500 grams.

The average weight of our macrosomes is $4249.79 \mathrm{~g}$ with a weight of $4970 \mathrm{~g}$ for the highest weight.

Two-thirds of newborns macrosomes are male. This makes a sex ratio of 2 to 1. Almost all (99\%) of newborn macrosomes had a good APGAR (>7).

\subsection{Maternal and Fetal Complications}

The most common complication mother in the delivering of macrosomes is the first degree of perinea tear (Table 2). Almost two third (2/3) of patients were free of complications after delivery.

The observed fetal complications were transiting. 6 cases of hypoglycemia occurred in $4.25 \%$ of cases. 5 cases of respiratory distress (3.54\%) and 6 cases of shoulder dystocia.

There were not traumatic lesions (4.25\%).

\section{Discussion}

\subsection{Anthropometric and Epidemiological Characteristics}

The frequency of newborn macrosomes goes according to the studies and especially the countries [2]. Our rate $(7.95 \%)$ is close to the rates collected by

Table 2. Maternal and fetal complications.

\begin{tabular}{lcc}
\hline lesions & Number & Percentage (\%) \\
\hline Tear 1st degree & 28 & 19.85 \\
Tear 2nd degree & 8 & 5.68 \\
Tear 3rd degree & 3 & 2.12 \\
Hemorrhage of deliverance & 6 & 4.25 \\
None & 96 & 68.10 \\
Total & 141 & 100 \\
\hline
\end{tabular}


Bromwich (8\%) in Europe [3] and Jason A. (7.6\%) in the USA [4]. In China, rates vary by region, but are generally close to our rates [5]. In the United States, $\mathrm{K}$ Rockhill is found to have a twice as high prevalence of a $14 \%$ macrosome in the Alaska population as a population at risk for macrosomia [6]. This prevalence decreases very markedly when only macrosomes greater than $4500 \mathrm{~g}$ are consided, with levels varying between $1 \%$ and $1.5 \%$ [7]. All its results confirm the variability of the frequency according to the population studied and the weight considered defining the macrosomia (4000 g or $4500 \mathrm{~g}$ ). In our study, 2/3 of the macrosomes were born to Caucasian mothers.

Almost half of our patients were under the age of 30 at the time of delivery with an average age of 30 years. These results are close to those of Matthew $\mathrm{C}$. [8]. On the other hand, Horan and Al. Find a slightly higher average age, which is 32.89 [9] [10]. Moreover, it is commonly accepted that a maternal age of more than 35 years is strongly associated with a risk of fetal macrosomia especially when associated with high parity [2].

Half of our patients had an IMC less than 25, contrary to what would have been expected because the high BMI is a known risk factor for macrosomia [4].

\subsection{Antecedents}

The antecedents of type 1 diabetes, type 2 diabetes or gestational diabetes were rarely found in our patients. The reason would be that these patients at risk of macrosomia were particularly well followed and considered their antecedent allowed to control their weight gain. However, one in five patients had a history of macrosome delivery. Frequently situation found by several authors [10].

\subsection{Clinical Features of Pregnancy and Childbirth}

About 1 out of 5 patients had gestational diabetes during the current pregnancy. This is quite important. Most of her diabetes was balanced and under diet (97\%), and diabetes was detected during pregnancy. This explains the importance and relevance of screening and correct management of diabetes during pregnancy to avoid or prevent complications during childbirth [2]. It is also important to note the role of diet during pregnancy in diabetic mothers [9]. Weight gain during pregnancy was in more than half on the cases above normal (above $12 \mathrm{~kg}$ ). The results reported by other authors are exactly the same as ours [9].

$1 / 4$ of the deliveries were by caesarean section and $2 / 3$ of the caesarean sections were in emergency. Our results confirm the maternal risk of Caesarean section in macrosome deliveries, as it is shown by many authors [10] [11]. The rate of delivery by normal childbirth procedure is close to $75 \%$. Thus confirming that macrosomia should not be a systematic indication of caesarean section [12] [13] [14], it should also be in mind that $1 / 3$ of the delivery triggers resulted in an emergency Caesarean section when the fetus was macrosome.

\subsection{Characteristics of Newborns}

The sex ratio of the macrosomes in our study is 2 for 1 . This predominance of 
the male sex is found in all the studies and in the same proportions whatever the authors and the region [2] [5] [10] [15] [16].

Almost all of our newborns had a good APGAR (above to 7). We used instrumental extractions once in six or an emergency caesarean when there was an alteration of the fetal heart rate or the non-progression of the fetal mobile at the end of work. We have noted three cases of shoulder dystocia reduced by Marc Robert's maneuver. There were earlier difficulties on the shoulders than real shoulder dystocia. Hence the absence of traumatic lesions observed in our series. Some newborns had hypoglycemia taken care of promptly by the pediatrician with an average duration of 36 hours in neonatology. All her newborn babies went out with their mother. No macrosomes were transferred to a higher level after birth. Most of the complications usually expected in macrosome deliveries have not been observed in our series [10] [15].

\subsection{Maternal Complications}

The most noticed maternal complications in our series are the perineo-vaginal tears ( 39 cases) and the hemorrhages of the delivery ( 6 cases).

The most serious lesions were the tears of the complete perineum which in two cases occurred without episiotomy and in one case after an episiotomy surely not wide before an instrumental extraction. This still puts the interest of the episiotomy for obstetric maneuvering during childbirth [12] [16].

These maternal complications are described by several authors and their care has not caused particular difficulties [17]

\section{Conclusion}

Macrosomia is a common issue in the Center Hospital of Montélimar. This macrosomia predominates in the Caucasian race. Most of the patients had no history of gestational diabetes and did not give birth in a context of gestational diabetes. Patients were predominantly young and pauciparous with a BMI less than 25. Weight gain of more than $14 \mathrm{~kg}$ was frequently found. Normal childbirth is the main delivery route in our department with spontaneous deliveries at term and sometimes after term (41SA - 42SA). There are twice as many male 11 than female. On the whole, the deliveries were well run with very few maternal and fetal complications.

\section{References}

[1] Meredith, H.V. (1970) Body Weight at Birth of Viable Human Infants: A Worldwide Comparative Trease. Human Biology, 42, 217-264.

[2] CNGOF (1995) Exract from the Gynecological Obstetrics Updates. Twentieth National Days, Paris. Tome XIX.

[3] Bromwich, P. (1986) Big Babies (Editorial). The BMJ, 293, 1387-1388. https://doi.org/10.1136/bmj.293.6559.1387

[4] Jason, A., Pates, D.D., Mclntire, B.M. and Casey, K.J. (2008) Leveno: Predicting Macrosomia. Journal of Ultrasound in Medicine, 27, 39-43. 
https://doi.org/10.7863/jum.2008.27.1.39

[5] Li, G., et al. (2015) Prevalence of Macrosomia and Its Risk Factors in China: A Multicentre Survey Based on Birth Data Involving 101723 Singleton Term Infants. Http://www.ncbi.nlm.nih.gov/pubmed/24891149

[6] Rockhill, K., Dorfman, H., Srinath, M. and Hogue, C. (2015) The Effects of Pregnancy Body Mass Index and Gestational Weight Gain on Fetal Macrosomia among American Indian/Alaska Native Women. Maternel and Child Health Journal, 19, $1-12$.

[7] Megafu, U. and Ozumba, B.C. (1988) Obstetric Complications of Macrosomic Babies in African Women. International Journal of Gynecology \& Obstetrics, 26, 197-202. https://doi.org/10.1016/0020-7292(88)90262-7

[8] Matthew, C., Neil, J. and John, P. (2003) Harris, Stéphen Robinson. Risk Factors for Macrosomia a Ditz Clical Consequence: A Study of 350311 Pregnancies. European Journal of Obstetrics \& Gynecology and Reproductive Biology, 111, 9-14. https://doi.org/10.1016/S0301-2115(03)00154-4

[9] Horan, et al. (2015) The Association between Maternal Dietary Micronutrient Intake and Neonatal Anthropometry Secondary Analysis from the ROLO Study. $\mathrm{Nu}$ trition Journal, 14, 105. https://doi.org/10.1186/s12937-015-0095-Z

[10] Chatfield, J. (2001) Practice Guidlines: ACOOG Issues Guidelines on Fetal Macrosomia. American Family Physician, 64,169-170.

[11] Zamorski, M.A. and Biggs, W.S. (2001) Management of Suspected Fetal Macrosomia. American Family Physician, 63, 302-307.

[12] Recommandations issues de l'ACOG practice: Clinical Management Guidelines for 0bstetrician-Gynecologists, Number 22, November 2000.

[13] Delpapa E.H. and Mueller-Heubach, E. (1991) Pregnancy Outcome Following U1trasound Diagnosis of Macrosomia. Obstetrics \& Gynecology, 78, 340-343.

[14] Sandmire, H.F. (1993) Whither Ultrasonic Prediction of Fetal Macrosomia? Obstetrics \& Gynecology, 82, 860-862.

[15] Nkwabong, E. and Nzalli Tangho, G.R. (2015) Risk Factors for Macrosomia. Journal of Obstetrics and Gynecology of India, 65, 226-229. https://doi.org/10.1007/s13224-014-0586-4

[16] Yadav, H. and Lee, N. (2014) Factors Influencing Macrosomia in Pregnant Women in a Tertiary Care Hospital in Malaysia. Journal of Obstetrics and Gynaecology Research, 40, 439-444. https://doi.org/10.1111/jog.12209

[17] Stotland, N., Caughey, A., Breed, E., et al. (2004) Risk Factors and Obstetric Complications Associated with Macrosomia. Obstetrics and Gynecology, 87, 220-226. https://doi.org/10.1016/j.ijgo.2004.08.010 
Submit or recommend next manuscript to SCIRP and we will provide best service for you:

Accepting pre-submission inquiries through Email, Facebook, LinkedIn, Twitter, etc. A wide selection of journals (inclusive of 9 subjects, more than 200 journals)

Providing 24-hour high-quality service

User-friendly online submission system

Fair and swift peer-review system

Efficient typesetting and proofreading procedure

Display of the result of downloads and visits, as well as the number of cited articles Maximum dissemination of your research work

Submit your manuscript at: http://papersubmission.scirp.org/

Or contact ojog@scirp.org 